\title{
Contribuições do Curso Intercultural Indígena na Práxis dos Professores da Etnia Karipuna-Ap
}

\author{
Iranir Andrade dos Santos \\ Universidade Estadual do Ceará - UECE \\ Alexandre Almeida Barbalho \\ Universidade Estadual do Ceará - UECE
}

\begin{abstract}
Resumo
Esta pesquisa intitulada Contribuições Do Curso Intercultural Indígena na Práxis dos Professores Da Etnia Karipuna-AP teve como objetivo geral analisar as contribuições do curso de licenciatura intercultural indígenas para a práxis pedagógica dos professores indígenas da etnia Karipuna-Oiapoque/AP. A metodologia utilizada foi de investigação quali-quantitativa, a qual norteou todas as etapas desse estudo, pois permitiu, através da interpretação dos dados, descrever e analisar os fenômenos envolvidos no meio em que vivemos. Fundamentou-se em um estudo de caso, por buscar a compreensão dos saberes de uma realidade específica no contexto particular, bem como ressalta que as evidências entre as abordagens são complementares para compreensão complexa dos fatos pesquisados. Os resultados indicaram que o egresso pode influenciar positivamente seus alunos e a comunidade a fim que de a realidade local seja construída a partir de suas necessidades, dando visibilidade a própria ideologia do povo Karipuna. Com isso, o professor - egresso é tão respeitado a ponto de elegerem como cacique e vice-cacique
\end{abstract}

Palavra-chave políticas públicas; indígenas; docência; caripuna; práxis.

\begin{abstract}
This research entitled Contributions of the Indigenous Intercultural Course in the Praxis of Teachers of the Ethnicity Karipuna-AP had the general objective of analyzing the contributions of the intercultural degree course to the pedagogical praxis of indigenous teachers of the ethnic Karipuna-Oiapoque / AP. The methodology used was a qualitative and quantitative investigation, which guided all stages of this study, as it allowed, through the interpretation of the data, to describe and analyze the phenomena involved in the environment in which we live. It was based on a case study, as it seeks to understand the knowledge of a specific reality in the particular context, as well as emphasizing that the evidence between the approaches is complementary for a complex understanding of the
\end{abstract}


researched facts. The results indicated that the graduates can positively influence their students and the community so that the local reality is built from their needs, giving visibility to the very ideology of the Karipuna people. With that, the professor - egress is so respected as to elect as chief and vice-chief

Key-word public policy; indigenous people; teaching; caripuna; praxis.

\section{Introdução}

Este estudo pauta-se na educação para os povos indígenas como forma de respeitar os grupos étnicos diferenciados, com direito a manter sua organização social, costumes, línguas, crenças e tradições, o que nos leva a acreditar que é possível trabalhar e incentivar cada vez mais as políticas educacionais indigenistas.

Com a Constituição de 1988, os povos indígenas passaram a ter uma legislação específica que legitima sua diferença étnica dentro do território nacional, assegurando-lhes o uso de suas línguas maternas, de sua cultura própria e de seus territórios tradicionais, sendo que sua história e estruturas sociais ficam protegidas por lei e devem ser respeitadas em todas as instâncias do território brasileiro. Ainda nesse viés existem vários documentos que relatam e que pretendem assegurar aos indígenas seus direitos, mas nenhum deles nos mostra de forma clara que os índios estejam sendo de fato ouvidos ou fazendo parte da elaboração dos mesmos.

Nesse cenário observa-se uma preocupação com as políticas indígenas a qual nos mostra que a questão das políticas públicas destinadas à educação voltada para os indígenas foi historicamente negada a eles e nesse ínterim desenvolver um trabalho que vise abordar essa temática nos leva a crer que é possível tentar amenizar essa dívida educacional e social.

\section{Origem do estudo}

Diante da realidade amapaense, este estudo se propõe a aprofundar conhecimentos, produzir saberes e integrar a sociedade na direção de uma ampliação nas discussões, acerca do índio, problematizando e analisando seus desafios, avanços e retrocessos em um tempo histórico que ainda concebem-nos sob a lógica assistencialista e compensatória. Com isso o presente trabalho traz como relevância a alteridade como forma de conhecer a diferença, não como ameaça a ser destruída, mas como alternativa a ser preservada.

No que se refere à relevância pessoal deste estudo, destaca-se que enquanto profissional da educação no Amapá, esta estudante é responsável pela a disciplina Educação Escolar Indígena, e com isso percebemos a necessidade de buscar discussões em torno das políticas públicas para a educação superior destinada aos indígenas.

Com relação à importância acadêmica, esta pesquisa poderá contribuir significativamente para despertar maiores interesses às questões indigenistas, assim como incentivar sua valoração cultural. Pela falta de leitura da população local poucos têm interesses em ingressar na temática voltada para os indígenas.

Assim, torna-se cada vez mais importante o estudo das políticas públicas destinadas à educação superior para os indígenas como forma de se delinear estratégias para a melhor condução das questões culturais de cada etnia. Para isso precisamos ouvir os egressos do curso intercultural indígena como elemento integrador de um ensino de qualidade e o que 
esses indígenas definem como qualidade de ensino na construção de uma educação a partir de seus parâmetros culturais.

Desta forma, o trabalho tem como problema: Quais as contribuições do curso licenciatura intercultural indígenas para a práxis pedagógica dos professores indígenas da etnia Karipuna - Oiapoque/AP? Como objetivo geral: Analisar as contribuições do curso de licenciatura intercultural indígenas para a práxis pedagógica dos professores indígenas da etnia Karipuna no município de Oiapoque/AP;

\title{
Contexto da experiência avaliada
}

Observando que os povos indígenas por muito tempo tiveram sua educação pautada na catequização, civilização e integração, vítimas de atrocidades impostas pela sociedade não indígena, com objetivo de negar a diferença, fazendo com que os conhecimentos e saberes indígenas fossem ignorados, para assim, aprender e utilizar os saberes da cultura dominante e por muito tempo os indígenas conviveram com essa situação, desse modo, as comunidades indígenas passaram a reivindicar a escola como espaço de constituição de saberes e melhorias na formação de seus professores, sem perder a afirmação de sua identidade. Nessa perspectiva, primeiramente temos como agentes principais os próprios povos indígenas, seus representantes e organizações. Para Maria Helena Sousa da Silva Fialho (2012, p. 51):

\begin{abstract}
Com a extinção do SPI no auge de uma crise no seu quadro institucional agregada de denúncias de corrupção, com evidências de que o mesmo estava satisfazendo interesses econômicos e não cumprindo de fato o seu papel de instituição indigenista voltada para a defesa dos interesses e direitos indígenas, uma nova organização foi instituída. O governo brasileiro criou em 1967 a Fundação Nacional do Índio - FUNAI, através da Lei 5.371 a qual ficou subordinada ao antigo Ministério do Interior e teria como meta importante "suprir as deficiências do SPI (...).
\end{abstract}

Após essa investida do governo brasileiro, o amadurecimento progressivo do movimento indígena desde a década de 1970 e o consequente crescimento no número e diversidade de organizações nativas, dirigidas pelos próprios índios, nos sugere assim uma primeira distinção no campo indigenista: a "política indígena", aquela protagonizada pelos próprios índios, não se confunde com a política indigenista e nem a ela está submetida. Entretanto, boa parte das organizações e lideranças indígenas vem aumentando sua participação na formulação e execução das políticas para os povos indígenas. (MARCONI, 2009).

No Estado do Amapá, mais especificamente os Povos do Oiapoque houve um avanço realizado pela a Associação dos Povos do Oiapoque - APIO, tanto nas questões educacionais, como políticas e ambientais.. Porém, a organização dos indígenas é um processo de lutas que visa à garantia dos seus direitos.

Quanto a Lei 11.645/2008 é um desmembramento da Lei no. 9.394, de dezembro de 1996, ao disciplinar a educação escolar indígena passa a ser trabalhada de uma forma que tenha um currículo flexível. No "Art. 78 - O Sistema de Ensino da União, com a colaboração das agências federais de fomento à cultura e de assistência aos índios, desenvolverá programas integrantes de ensino e pesquisa, para a oferta de educação bilingue 
intercultural aos povos indígenas." A partir dessa lei os avanços ainda são muito tímidos diante da necessidade.

Com a Constituição de 1988, os povos indígenas passaram a ter uma legislação específica que legitima sua diferença étnica dentro do território nacional, assegurando-lhes o uso de suas línguas maternas, de sua cultura própria e de seus territórios tradicionais, sendo que sua história e estruturas sociais ficam protegidas por lei e devem ser respeitadas em todas as instâncias do território brasileiro. Em 2018 em uma entrevista concedida a Carlos Barros Gonçalves, Prezia diz:

\begin{abstract}
Estamos vivendo um grave momento de retrocesso político institucional, em que a sociedade brasileira assiste, perplexa, não só denúncias envolvendo políticos e instituições brasileiras, como também o desmonte de muitos programas sociais e conquistas, com graves consequências para o país, sobretudo para a população de baixa renda. A partir do impeachment da ex-presidente Dilma, que na realidade foi um golpe branco, as forças direitistas, cada vez mais articuladas no Congresso Nacional têm feito uma forte ofensiva contra os direitos dos povos indígenas, sobretudo em relação à terra, base vital para esses povos. (...).
\end{abstract}

A preocupação de Prezia para com as questões da população indígena era exatamente chamando à atenção para que esses não tenham seus direitos usurpados por um governo que não valoriza e muito menos respeita as minorias.

Especificamente no Estado do Amapá, as políticas de educação escolar indígena são baseadas na legislação. As comunidades ainda não possuem um projeto político pedagógico. Esse está em fase de construção na comunidade dos Wajãpi's para posterior ser acompanhado a criação dos PPP's nas demais TI.

Quanto as TI a população de acordo com o Instituto de Pesquisa e Formação Indígena (TI) que habitam o Amapá temos:

- Os Wajãpi que vivem na TI Wajãpi e somam mais de 1000 pessoas, distribuídas em 49 pequenas aldeias. (IBGE, 2010) sendo o ultimo censo. Os quatro povos que habitam a região do baixo Rio Oiapoque falam línguas aruak (os Palikur), carib (os Galibi-Kali'na) e patoá (os Karipuna1e os Galibi-Marworno). O Complexo do Tumucumaque que é constituído pelas TI Parque do Tumucumaque e Paru D’Este, situadas, em sua maior parte, no Estado do Pará. Este complexo situa-se na região em que o Brasil faz fronteira com o Suriname. Nele encontra-se em maior número os Tiriyó e Kaxuyana, que atualmente somam cerca de 1550 pessoas.

As aldeias localizadas mais próximas de um campus são algumas do Município de Oiapoque - mas isso significa dizer que são $30 \mathrm{~km}$ do pólo base ao campus. As aldeias do Parque Montanhas do Tumucumaque só transitam via transporte aéreo. Nas TI do

1 Os Karipunas fazem parte do complexo de povos indígenas da região do baixo rio Oiapoque que estão inseridos em redes amplas de intercâmbio que englobam famílias índias ou não-índias estabelecidas em aldeias e cidades vizinhas no Brasil e na Guiana Francesa. A despeito de tratar-se de uma sociedade com fronteiras pouco precisas, fluidas e indefinidas, dados os constantes intercâmbios, intercasamentos e realocações das famílias, os Karipuna utilizam a expressão "nosso sistema" para definir um conjunto de práticas, conhecimentos e crenças que consideram próprias, englobando conhecimentos xamanísticos e católicos. 
Município de Pedra Branca do Amapari a distância da capital é em torno de 5 horas de transporte terrestre e parte da estrada não é pavimentada.

Para ingresso temos as cotas que pelo quantitativo não atende a demanda. A outra dificuldade é a permanência no nível superior, pois além da dificuldade de locomoção, também tem a questão do idioma e muitos não têm onde ficar, alguns vão para casa de parentes, amigos e enfrentam também a discriminação.

A Universidade Federal do Amapá oferta o curso licenciatura intercultural indígena e o ingresso é somente para os indígenas, o que vem garantir um processo seletivo diferenciado. Sendo esse fruto de lutas do movimento social indígena. A universidade estadual ainda não dispõe de uma seleção específica para esses povos. Apenas possui as cotas e a bolsa permanência. Porém, não são específicas. Mas está em fase de implantação do processo seletivo diferenciado.

No primeiro semestre de 2018 houve uma pressão popular por parte dos indígenas para que tivessem acesso a outros cursos do campus binacional - a ação teve também questionamentos da comunidade quilombola e deu origem a resolução CONSU N. 21/2018, de 5 de junho de 2018 que aprova e regulamenta o Processo Seletivo Extraordinário para Indígenas e Quilombolas (PSEIQ), para ingresso nos cursos de graduação do Campus Binacional de Oiapoque, no segundo semestre letivo de 2018.

Em 2019 é extinta a SECADI - Secretaria de Educação Continuada, Alfabetização e Diversidade e Inclusão são extintas - um órgão componente da estrutura administrativa do Ministério da Educação (MEC) criada no ano de 2004 tinha como objetivo fortalecer a relação dos grupos historicamente excluídos da escolarização com a sociedade. Consideravam "questões de raça, cor, etnia, origem, posição econômica e social, gênero, orientação sexual, diferenças, condição geracional e outras que possam ser identificadas como condições existenciais favorecedoras da exclusão social", bem como a CoordenaçãoGeral de Educação Escolar Indígena/MEC - CGEEI, além da Gestão Territorial e Econômico dos Povos Indígenas. Se com o status de secretaria que havia toda uma disponibilidade financeira para trabalhar a educação escolar indígena e demais ações voltadas para esse povo já era complexo, imagina atualmente como um departamento.

Referente ao curso licenciatura intercultural indígena a Resolução do Conselho Nacional de Educação - CNE/CEB no 3/1999 sobre às diretrizes curriculares nacionais da educação escolar indígena diz que tem toda uma legislação a ser atendida de acordo com a realidade local, dentre elas a Fundamentação, Conceituações da Educação Indígena; Criação da Categoria Escola Indígena; - Definição da Esfera Administrativa; - A Formação do Professor Indígena; - O Currículo e sua Flexibilização; - Flexibilização das Exigências e das Formas Contratação de Professores Indígenas; - Estrutura e Funcionamento da "Escola Indígena".

Sobre a origem e criação do curso licenciatura intercultural indígena criado em setembro de 2006 pela Resolução no 021/06, CONSU/UNIFAP o curso vem para atender uma política pública educacional para o nível superior dos povos indígenas do Estado do Amapá e adequado a realidade local em diálogo com as lideranças das aldeias. 0 Curso Licenciatura Intercultural Indígena já existe em mais de 20 universidades públicas e vem também para estimular a autoestima e valorização dos saberes indígenas. Na Universidade Federal do Amapá, as primeiras discussões se deram com o projeto político pedagógico para o curso Licenciatura em Educação Escolar Indígena - PPPEEI em 2005, que uniu várias instituições e organizações indígenas e não indígenas que atuaram na construção do curso. 
Entre esses, o conselho de educação, a UNIFAP, camara de vereadores d Oiapoque, FUNAI Amapá, FUNAI Oiapoque, SEED/Amapá, FUNASA, etc... Com o PPPEEI a:

\begin{abstract}
proposta é resultado das discussões desenvolvidas no âmbito do Grupo de Trabalho Interinstitucional Portaria n. ${ }^{-}$859/UNIFAP, de 26 de novembro de 2003, que foi criado com o propósito de discutir e propor medidas que garantam o acesso de indígenas ao ensino superior, processo desenvolvido a partir de abril 2003 até dezembro de 2005. (PPPEEI, 2005, p. 6).
\end{abstract}

Mostra o inicio da luta dos movimentos sociais indígenas diante da universidade para que a educação superior seja garantida atendendo às peculiaridades da comunidade e suas especificidades, pois já havia tentativa de indígenas adentrarem a educação superior. Porém, não conseguiam, pois a nota de corte é muito alta para o nível de ensinamento que eles já haviam recebido. Em sua maioria, o ensino médio foi proveniente do "sistema modular de ensino e esse não era específico para os povos indígenas" (PPPEEI, 2005).

O campo de atuação desses futuros profissionais são as escolas das áreas indígenas.

Pelo projeto político pedagógico do curso licenciatura intercultural indígena PPPCLII a matriz curricular esta ligada ao tipo de educação que se pretende assegurar para essa determinada população, bem como para que os mesmos consigam dirigir sua própria educação no futuro. Para isso, foi criada uma matriz conceitual com temas contextuais de formação geral com um conjunto de conhecimentos com competências e com uma carga horária de $2.145 \mathrm{~h}$, do incio do curso ao 4 semestre, que envolve a temática dos povos indígenas e a legislação indigenista, fundamentos pedagógicos da educação escolar indígena, povos indígenas no amapá e norte do pará, política de revitalização cultural e linguisitca, saúde e educação indígena, organização e legislação da educação escolar indígena, cultura, identidade e educação, didatização para a escola indígena I, prática de ensino I, estágio supervisionado em docencia I e atividades artistico-culturais.

\title{
Campo de estudo
}

A pesquisa apresenta a estrutura de investigação quali-quantitativa, pois de acordo com Gunther (2006), a mesma permitiu, através da interpretação dos dados, descrever e analisar os fenômenos envolvidos no meio em que vivemos. Além disso, Yin (2010) ressalta que as evidências entre as abordagens, em estudos de casos, são complementares para compreensão complexa dos fatos pesquisados. Fundamentamos em um estudo de caso, por buscarmos a compreensão dos saberes de uma realidade específica no contexto particular, o que para Yin (2010) pode contribuir com o conhecimento dos fenômenos individuais, grupais, organizacionais e sociais da realidade ali existente.

A área de estudo foi com o povo Karipuna por residirem mais próximos entre si. Distante da capital do Estado do Amapá, Macapá, $650 \mathrm{~km}$ via transporte terrestre em uma estrada que tem asfalto por $400 \mathrm{~km}$. 


\section{Resultado final}

Os elementos levantados são originados das entrevistas e observações das aulas dos egressos que também são levados em consideração, suas concepções e análises referente ao curso LII. Assim, foram organizados os dados de modo que os objetivos fossem contemplados.

As entrevistas foram realizadas com 6 docentes indígenas que nos mostram como é esse saber construído a partir da formação que obtiveram no curso licenciatura intercultural indígena, bem como suas possíveis contribuições. Na ordem seguem as entrevistas realizadas, são elas com as seguintes aldeias: Aldeia Manga, Taminã e Açaizal, que fizemos no dia 22/10/2018, as demais foram no dia 23/10/2018: Pacapuá, Santa Izabel e Espirito Santo. Nesse momento a pesquisa de campo em muito vem para ajudar nas buscas da respostas ou não da problemática desse estudo.

Quanto às práxis pedagógica dos professores Karipuna do Baixo Rio Curipi, a escola da ALDEIA MANGA cujo nome é Escola Indígena Estadual Jorge Iaparra, possui toda a educação básica

Com as observações pude perceber como se dá esse saber pedagógico, bem como a ideologia da etnia Karipuna. Um povo que busca em coletivo trabalhar a educação de suas crianças e adolescentes de forma dinâmica envolvendo a docência e suas práticas sociais.

Pelas entrevistas e observações, as disciplinas trabalhadas no projeto político pedagógico do curso de licenciatura intercultural indígena em muito contribuiu durante a formação geral para que esses egressos pudessem despertar da riqueza local do ponto de vista da pesquisa com os seus alunos e abordando os princípios filosóficos/pedagógicos e legais da educação escolar indígena.

Também pude perceber que, em muito a educação escolar indígena, mesmo com todas as dificuldades, está voltada para defesa do território, do ambiente, do fortalecimento da cultura e das identidades dos povos e, principalmente na valorização do saber local.

Todos os egressos entrevistados e observados se preocupam em construir atividades de nivelamento para os alunos com baixo desempenho na disciplina, isso foi uma questão que foi também trabalhado durante a formação superior no LII. Em relação ao planejamento das aulas entre os professores, se o curso ensinou a proporcionar esses momentos, parte deles não relataram nem nas entrevistas e nem na observação. Mas, percebemos que realizam seus planejamentos individuais. A aldeia com mais estrutura, inclusive com energia 24h, a Manga, tem esses momentos de planejamento, pois também dispõe de coordenação pedagógica que consegue dá um suporte maior para os professores e alunos.

O saber pedagógico e a Ideologia Karipuna são construídos coletivamente, envolvendo a comunidade e seu jeito próprio de ser. Um povo com peculiaridades distintas, mas que em muito se preocupam em fazer educação à sua maneira. A natureza é parte desse saber, tanto que o calendário da escola leva em consideração o plantio e colheita nas roças e as crianças e adolescentes muito ajudam para o sucesso desse trabalho, mas alguns pais até liberam esse adolescente para estudar, preocupados com o futuro desses. "Porém, tem alguns adolescentes que usam de esperteza e, simplesmente, não se dedicam aos estudos como deveriam para não irem para a roça trabalhar" - Fala de um docente. Mas, no geral a maioria ajuda os pais. 
Quanto à práxis pedagógica observada nas salas de aula, muito docentes informaram que foi construída a partir da formação no CLII e que só tem melhorado. Aprenderam a ser mais criativos e, com isso incentivam a construção do conhecimento nas crianças e adolescentes. Também melhorou a relação com a comunidade, pois se sentem mais respeitados. Para Selma Garrido Pimenta:

\begin{abstract}
Uma identidade profissional se constrói, pois, a partir da significação social da profissão; da revisão constante dos significados sociais da profissão; da revisão das tradições. Mas também da reafirmação de práticas consagradas culturalmente e que permanecem significativas. Práticas que resistem a inovações porque prenhes de saberes válidos às necessidades da realidade. (...). (1999, p. 19)
\end{abstract}

A fala da autora no leva a considerar a autonomia do profissional docente e o quanto esse pode influenciar positivamente seus alunos e a comunidade, a fim de que a realidade local seja construída a partir de suas necessidades, dando visibilidade a própria ideologia do povo Karipuna. Com isso, o professor egresso é tão respeitado a ponto de a comunidade de elegê-lo como cacique e vice-cacique.

\title{
Proposições
}

Este estudo teve como objetivo analisar as contribuições do curso de licenciatura intercultural indígenas para a práxis pedagógica dos professores indígenas da etnia Karipuna e buscamos por diferentes caminhos perseguir esse objetivo e o mesmo felizmente foram alcançados com êxito. Percebemos na pesquisa de campo que em muito a fala do autor contribui para o engajamento desses indígenas nessa construção de sua educação escolar do seu jeito e com suas peculiaridades.

No que se trata das políticas públicas para os indígenas, percebemos que também é um desafio colocar em prática o que a Lei 11.645/2008, que é um desmembramento da Lei 9.394, de dezembro de 1996, ao disciplinar a educação escolar indígena para ser trabalhada de forma que tenha um currículo flexível. Depois da formação no CLII é que esses docentes se sentiram mais seguros em colocar em prática seus conhecimentos referente às políticas públicas e leis que os asseguram em quanto seres donos dos seus processos sociais.

Vi que CLII é uma política pública fruto da luta dos povos indígenas em busca de formação superior. Muito eles fizeram para que de fato esse curso fosse efetivado aos moldes de suas reais necessidades. Para isso, a questão da política educacional e a valorização da cultura de saberes indígenas tratam de uma realidade que juntos podemos ajudar para que, de fato, seja efetivada, já que em um país democrático, todo cidadão tem direito à educação e neste caso, especialmente à educação escolar indígena, para que esse povo possa se sentir parte e devidamente serem acolhidos no sistema educacional voltados para o ensino superior e posterior formação continuada.

Nas observações, percebemos a satisfação em exercer o papel de professor, parecia ser um sonho jamais alcançado. O CLII que, está sendo reformulado, vem melhorar o envolvimento desse futuro profissional indígena frente a sua realidade local. Então, quanto ao curso foi verificado na pesquisa de campo, que os pontos positivos sobrepõem aos negativos. 
Verificamos ao realizar a pesquisa de campo, o que Geertz diz referente aos vários conceitos de cultura. Foi de fato evidenciado, ou seja, varia muito de uma comunidade para outra. Uma só fala, a língua portuguesa, a outra vizinha, é muito presente, o kheol.

Com o objetivo central desse estudo vimos que foi trabalhado de forma que, na fala dos indígenas docentes entrevistados e observados, o curso deixa um legado de conhecimento e satisfação, mas que não pretendem parar somente na graduação.

Como principais resultados desse estudo, verificamos que, quanto ao problema da pesquisa, esse foi visto de forma que a práxis docente vem influenciando de forma positiva a vivência das comunidades, bem como esses profissionais são fonte de inspiração para as crianças e adolescentes. Além de que, em relação aos compromissos do GEA, ficou evidente a ausência do Estado quanto à educação escolar para os povos indígenas. Escolas em madeira totalmente destruída pelo tempo. Cadeiras e mesas inadequadas para estudos, sala de aula sem a devida iluminação, nem mesmo a natural. Fios elétricos colocados direto no concreto, onde deveria haver conduíte. Goteiras nas salas de aula. Uma total ausência de estrutura para alunos, professores e a gestão das escolas para realizarem seu trabalho. Observamos que esses profissionais possuem boa vontade, mas não dispõem de recursos financeiros para atender às demandas das escolas.

Dentro das políticas públicas e, em especial para esse público, os indígenas, é passível de solução dependendo da determinação política para essa finalidade, verificamos ser possível os seguintes caminhos:

- Destinar uma verba para cada comunidade, a fim de que o Cacique ou o conselho da comunidade administrem e façam a devida prestação de conta. Nesse segmento, em muito poderia melhorar as condições das escolas nessas aldeias;

- A outra possibilidade é destinar emendas parlamentares para atender, principalmente à questão da eletricidade $24 \mathrm{~h}$. Já nas comunidades de difícil acesso para instalar a eletricidade, essa deveria ter uma cota maior de combustível que garanta as $24 \mathrm{~h}$ de uso e isso pode facilitar para que algumas comunidades tenham o ensino ampliado, não necessitando se deslocar paras aldeias vizinhas, sendo que a aldeia onde há a educação básica é bem mais distante;

- A outra questão que já existe, mas que está em falta é a merenda das crianças. Isso tem prejudicado, pois as crianças são liberadas mais cedo e isso compromete a finalização dos conteúdos, e posterior atraso no calendário, além desse ter que ser construído respeitando às especificidades desse povo; Além de garantir transporte e o recurso para se manterem, pois para receber o único benefício que alguns possuem é mais gasto até chegar ao local.

Em campo pude perceber o quanto a vida desses indígenas não é fácil. Um povo com sede de conhecimento, mas que não possui o básico para alcançar tal estudo. Além das condições estruturais, também possuem a questão econômica que em muito tem atrapalhado para que esses consigam realizar seus anseios e desejos profissionais.

Por fim, nas categorias trabalhadas na análise de dados, evidenciamos a percepção dos professores participantes do estudo acerca das contribuições do CLII e nas mudanças na sua prática docente oportunizadas pela formação.

Enfim, esse estudo não se esgota aqui, mas é um início de uma trilha de pesquisa a ser desenvolvida dentro das limitações da educação escolar indígena, bem como a qualidade da educação. Este estudo se comprometeu em analisar por um viés da educação escolar 
indígena. Não nos aprofundamos sobre a exigência da educação como a falta de estrutura, limitações essas que pretendemos aprofundar em outra oportunidade e em outras pesquisas.

\section{Referências bibliográficas}

ASSOCIAÇÃO DOS POVOS INDÍGENAS DO OIAPOQUE - APIO. Plano de vida dos índios e organizações indígenas do Oiapoque. Oiapoque: APIO, 2009.

BRASIL. Ministério Da Educação. Universidade Federal Do Amapá. Pró-Reitoria De Ensino De Graduação, E Interiorização. Projeto Político Pedagógico Do Curso Educação Escolar Indígena. Macapá-AP, 2005.

BRASIL, Referencial Curricular Nacional para as escolas indígenas. Ministério da Educação e do Desporto, Secretaria de Educação Fundamental - Brasília; MEC/SEF.1988 Decreto no 6001, 19 de dezembro, 1973. Dispõe sobre o Estatuto do Índio. Diário Oficial [da] República Federativa do Brasil, Brasília, 21 dez. 1973.

. Constituição da República Federativa do Brasil. Brasília: Senado Federal, 1988.

. Lei de Diretrizes e Bases Educação Brasileira. Brasília: Senado Federal, 1996.

Ministério da Educação. Conselho Nacional De Educação. Resolução CNE/CEB no 3/1999. Brasília, 1999.

Ministério da Educação. Dossiê Iaphan 2 \{Wajãpi\} expressão gráfica e oralidade entre os Wajãpi do Amapá. Brasília: MEC, 2002.

Resolução 03/99/CNE. Fixa Diretrizes Nacionais para o funcionamento das escolas indígenas. Brasília: MEC, 1999.

FIALHO, Maria Helena Sousa da Silva. Do Araguaia ao Planalto: uma auto-análise da gestão de políticas públicas em educação escolar indígena. Brasília:[s.n], 2012.

GEERTZ, Clifford. A interpretação da cultura. Rio de Janeiro: Guanabara Koogan, 1978.

INSTITUTO BRASILEIRO DE GEOGRAFIA E ESTATISTICA. Disponível em: < http://www.ibge.gov.br/home/>. Acesso em : 20 jan.2015.

IEPÉ.Museu Kuahí. Turé dos povos indígenas do Oiapque. Museu do Índio - FUNAI - 1 Reimpressão 2014, 2009.

LUCIANO, Gersem dos Santos. 0 Índio Brasileiro: o que você precisa saber sobre os povos indígenas no Brasil de hoje. Brasília/MEC/LACED/Museu Nacional, 2006.

MARCONI, Marina de Andrade; PRESOTTO, Zelia Maria Neves. Antropologia: uma introdução. 7. ed. São Paulo: Atlas, 2009.

PRÉZIA, Benedito. História da resitência indígena: $\mathbf{5 0 0}$ anos de luta. São Paulo: Expressão Popular, 2017.

PIMENTA, Selma Garrido. Formação de professores: identidade e saberes da docência. In: PIMENTA, Selma Garrido. (Org). Saberes pedagógicos e atividade docente. São Paulo: Cortez Editora, 1999. 
TRIVIÑOS, A. N. S. Introdução à pesquisa em ciências sociais: a pesquisa qualitativa em educação. São Paulo: Atlas, 1987.

UniVersidade federal Do AMAPÁ. Projeto Pedagógico De Curso De Licenciatura Intercultural Indígena Com Alterações (Resolução 12/2011 - Consu/Unifap). Macapá,2011.

UNIDAS, Nações. Declaração das Nações Unidas Sobre os Direitos dos Povos Indígenas. Rio de Janeiro, 2008. YIN. R. K. Estudo de caso: planejamento e métodos. 3 ed., Porto Alegre: Bookman, 2005 p.32.

YIN. R. K. Estudo de caso: planejamento e métodos. 3 ed., Porto Alegre: Bookman, 2005 p.32. 